\title{
Enzymatic Fluorometric Assay for myo-Inositol Trisphosphate ${ }^{1}$
}

\author{
JAMES A. Shayman, ${ }^{2}$ Aubrey R. MORRison, AND Oliver H. LowRy
}

Department of Medicine, The University of Michigan Medical Center, Ann Arbor, Michigan 48109.0364, and Departments of Medicine and Pharmacology, Washington University Medical School, St. Louis, Missouri 63110

\author{
Received November 21, 1986
}

\begin{abstract}
The determination of myo-inositol trisphosphate by an enzymatic fluorometric assay is presented. The method involves the acid extraction of water-soluble inositol polyphosphates followed by separation by anion-exchange chromatography. Samples are subsequently neutralized by passage over a Dowex $\mathrm{Cl}^{-}$resin and elution with lithium chloride. Samples are then desalted with ethanol. Following dephosphorylation with alkaline phosphatase, free myo-inositol is measured enzymatically via the NAD-dependent oxidation to scyllo-inosose with myoinositol dehydrogenase. The efficiency of recovery, assay specificity, and an application to the measurement of inositol polyphosphates in hormone-stimulated tissue are discussed. (c) 1987 Academic Press, Inc.
\end{abstract}

KEY WORDS: inositol polyphosphate; fluorometry; enzymatic assay.

The hydrolysis of phosphatidylinositol 4,5-bisphosphate with the formation of free inositol polyphosphates is now regarded as an important step in signal transduction with calcium-mobilizing effectors (1-3). Specifically, inositol 1,4,5-trisphosphate has been demonstrated to mobilize calcium from intracellular stores (4-6).

The study of effector-induced phosphatidylinositol metabolism, however, has been largely limited to radiotracer studies. In these reports the elaboration of inositol polyphosphates is determined by changes in the activity of $\left[{ }^{3} \mathrm{H}\right]$ inositol-containing metabolites (often in the presence of lithium chloride to inhibit inositol 1-phosphatase activity). Alternatively, changes in inositol phosphates are inferentially determined by changes in

\footnotetext{
1 This work was supported by U.S.P.H.S. Grants 1 K08 AM 01479-01 (JAS), AM 030542 (ARM), and NS 08862 and American Cancer Society BC-4-28(OHL).

${ }^{2}$ To whom reprint requests should be addressed at current address: Nephrology Division, Department of Internal Medicine, The University of Michigan Medical Center, 3914 Taubman Center, Ann Arbor, MI 48109 0364.
}

the activity of ${ }^{32} \mathrm{P}$-containing phospholipids (7) or by comparison to other phosphatecontaining metabolites (8). The former technique is limited to those tissues which are able to incorporate $\left[{ }^{3} \mathrm{H}\right]$ inositol; such studies usually assume that all $\left[{ }^{3} \mathrm{H}\right]$ inositol-containing metabolites are at equal specific activity. This assumption has not been tested. The latter technique does not provide specific data on the individual inositol phosphates formed.

A practical method for determining inositol polyphosphate mass would therefore be useful. MacGregor and Matschinsky (9) have developed a sensitive enzymatic assay for the determination of myo-inositol mass. This method has been modified and utilized for the determination of inositol trisphosphate mass.

\section{METHODS}

Principles of the assay. The quantitative determination of inositol trisphosphate utilizes a multistep assay. It is based upon the 
separation of $\mathrm{IP}_{3}{ }^{3}$ by anion-exchange chromatography, dephosphorylation, and fluorometric enzymatic determination of the free inositol. Specifically, this involves eight distinct steps:

(1) Biological samples are extracted with trichloroacetic acid and neutralized by extraction of the trichloroacetic acid with diethyl ether.

(2) $\mathrm{IP}_{1}, \mathrm{IP}_{2}$, and $\mathrm{IP}_{3}$ are separated by anion-exchange chromatography on a Dowex formate resin and a stepwise elution with an ammonium formate and formic acid gradient.

(3) To remove the ammonium formate and formic acid, the separated $\mathrm{IP}_{3}$ is added to a second anion-exchange resin and eluted with $1.5 \mathrm{M}$ lithium chloride. The sample is dried and most of the lithium chloride is removed with anhydrous ethanol. The lithium-IP ${ }_{3}$ salt is insoluble in ethanol.

(4) $\mathrm{IP}_{3}$ is dephosphorylated with intestinal alkaline phosphatase forming free myo-inositol.

(5) Free myo-inositol is converted to 2scyllo-inosose with the myo-inositol dehydrogenase. The reaction is pulled to completion with malate dehydrogenase:

$$
\begin{aligned}
& \text { myo-inositol } \longrightarrow \text { 2-scyllo-inosose }
\end{aligned}
$$

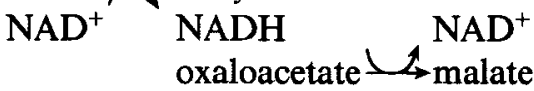

(6) The NADH and oxaloacetate are destroyed and the malate is converted back to oxaloacetate with malate dehydrogenase, yielding a stoichiometric amount of NADH. This reaction is pulled to completion with glutamate and aspartate transaminase:

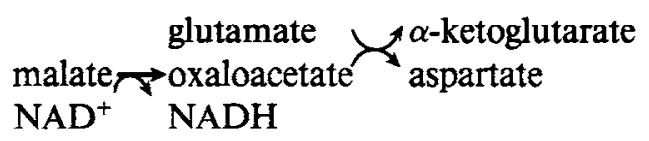

\footnotetext{
${ }^{3}$ Abbreviations used: $\mathrm{IP}_{1}$, mya-inositol monophosphate; $\mathrm{IP}_{2}$, myo-inositol bisphosphate; $\mathbf{I P}_{3}$, myo-inositol trisphosphate.
}

(7) To obtain the necessary sensitivity, the NADH formed is amplified with the enzymatic cycling method of Kato et al. (10), which utilizes alcohol dehydrogenase and malate dehydrogenase:

$$
\begin{array}{cc}
\text { oxaloacetate } & \longrightarrow \text { malate } \\
\text { NADH } & \text { NAD }^{+} \\
\text {acetaldehyde } & \text { ethanol }
\end{array}
$$

(8) The malate formed is then determined, coincidentally, by the same reactions as in step 6.

A protocol suitable for measuring 1 to 10 pmol of inositol trisphosphate and its application to primary cultures of renal papillarycollecting tubule cells are given below. This protocol, however, is also applicable to other biologic samples.

Step 1: Renal cell culture, hormonal stimulation, and sample extraction. Primary cultures of rabbit papillary-collecting tubule cells were harvested and grown as previously described (11). Cell cultures $\left(0.5\right.$ to $2.0 \times 10^{6}$ cells per dish) were rinsed three times with Krebs buffer and stimulated at $37^{\circ} \mathrm{C}$ with buffer alone or with bradykinin $\left(10^{-7} \mathrm{M}\right)$. Incubations were terminated by the rapid aspiration of buffer followed by the addition of 1 $\mathrm{ml}$ of ice-cold trichloroacetic acid (1 M). The precipitated protein and lipid were separated by centrifugation in an Eppendorf 5414 centrifuge. Protein was determined with the fluorescamine reagent (12). Aliquots $(500 \mu \mathrm{l})$ of supernatant from the trichloroacetic acidtreated samples were placed in $13 \times 100-\mathrm{mm}$ test tubes and extacted with $2 \mathrm{ml}$ of watersaturated diethyl ether. This extraction was repeated four times. The residual ether was evaporated by heating the samples to $65^{\circ} \mathrm{C}$ for $15 \mathrm{~min}$. The remaining traces of trichloroacetic acid in the ether-extracted samples were neutralized with $1 \mathrm{M}$ sodium bicarbonate (120 $\mu$ l for a $500-\mu l$ sample).

Step 2: Chromatographic separation. The entire sample was applied to a $0.75 \times 12-\mathrm{cm}$ column containing Dowex AG 1- $x 8$ formate 
form, anion-exchange resin (bed volume 1 ml) (Bio-Rad, Richmond, CA). Inositol and the inositol phosphates were serially eluted with (a) water $4 \mathrm{ml} 4 \times$; (b) $0.025 \mathrm{M}$ ammonium formate $4 \mathrm{ml} 2 \times$; (c) $0.2 \mathrm{M}$ ammonium formate, $0.1 \mathrm{M}$ formic acid $4 \mathrm{ml} 2 \times$; (d) $0.4 \mathrm{M}$ ammonium formate, $0.1 \mathrm{M}$ formic acid $4 \mathrm{ml}$ $2 \times$; and (e) $0.75 \mathrm{M}$ ammonium formate, 0.1 $M$ formic acid $4 \mathrm{ml} 2 \times$. These solvents eluted, respectively, inositol, glycerophosphatidyl inositol, $\mathrm{IP}_{1}, \mathrm{IP}_{2}$, and $\mathrm{IP}_{3}$. The success of this separation procedure has been reported by previous investigators (13). Positional isomers of the inositol phosphates, however, were not separated. A reduced concentration of ammonium formate was utilized in (e) so as not to include inositol tetrakisphosphate in the $\mathrm{IP}_{3}$ fraction (14).

Step 3: Desalting and neutralizing. Separated samples were desalted and neutralized by an adaptation of a recently reported protocol (15). Samples were diluted with $50 \mathrm{ml}$ of water and added to a second anion-exchange column (Dowex AG 1- x8, 200-400 mesh, chloride form, column size $0.75 \times 12$ $\mathrm{cm}$, bed volume $2 \mathrm{ml}$ ). The column was further washed with an additional $25 \mathrm{ml}$ of water. The inositol phosphates were then eluted with $8 \mathrm{ml}$ of $1.5 \mathrm{M} \mathrm{LiCl}$. Samples were brought to dryness in a vacuum centrifuge (Speed Vac, Savant). Trapped water was removed by resuspension of the lithium salts in $4 \mathrm{ml}$ of anhydrous ethanol and reevaporation. This was repeated three times. The dried pellet was resuspended in $8 \mathrm{ml}$ of absolute ethanol. The remaining lithium chloride containing the insoluble lithium phosphate salts was pelleted by centrifugation at $4000 \mathrm{~g}$ (Beckman J2-21 centrifuge). The supernatant was then removed. This procedure was repeated three times or until only a small pellet, barely visible, remained. Samples were then evaporated to dryness.

Step 4: Dephosphorylation of inositol polyphosphates. Samples were reconstituted in $50 \mu$ l of Tris buffer $(50 \mathrm{mM}, \mathrm{pH} 9.0$ ) containing $50 \mathrm{U} / \mathrm{ml}$ of bovine intestinal alkaline phosphatase and $5 \mathrm{mM} \mathrm{MgCl}_{2}$ and were incubated for $2 \mathrm{~h}$ at $37^{\circ} \mathrm{C}$. The alkaline phosphatase was reconstituted in $20 \mathrm{~mm}$ imidazole- $\mathrm{HCl}$ buffer $(\mathrm{pH} 7)$ containing $0.02 \%$ albumin before its addition to the Tris buffer. The alkaline phosphatase was then inactivated by heating the samples for $3 \mathrm{~min}$ in a boiling water bath.

Step 5: myo-Inositol oxidation. Initial steps were performed in $6 \times 50$-mm borosilicate, nitric acid-washed tubes. All enzymes suspended in ammonium sulfate were pelleted by centrifugation and resuspended in imidazole- $\mathrm{HCl}$ buffer (pH 7.0), containing $0.02 \%$ bovine serum albumin. An exception was myo-inositol dehydrogenase; this enzyme was reconstituted in $0.02 \mathrm{M}$ potassium phosphate buffer, pH 7.0 (see Results and Discussion).

myo-Inositol dehydrogenase reagent $(2 \mu \mathrm{l})$ was added to a 10- $\mu$ l aliquot of sample from step 4. This reagent consisted of Tris-HCl buffer $(350 \mathrm{mM}, \mathrm{pH} 9.0)$, oxaloacetate $(7$ $\mathrm{mM})$, malate dehydrogenase $(15 \mathrm{U} / \mathrm{ml})$, $\mathrm{NAD}^{+}(1.5 \mathrm{mM})$, and myo-inositol dehydrogenase $(1.0 \mathrm{U} / \mathrm{ml})$. After incubating at $25^{\circ} \mathrm{C}$ for $40 \mathrm{~min}$, excess oxaloacetate was destroyed by adding $0.5 \mu \mathrm{l}$ of $13 \mathrm{mM} \mathrm{H}_{2} \mathrm{O}_{2}$ and heating in a water bath at $75^{\circ} \mathrm{C}$ for $20 \mathrm{~min}$.

Step 6: Malate oxidation. NADH was generated next by the oxidation of malate to oxaloacetate with $10 \mu \mathrm{l}$ of malate dehydrogenase reagent. This consisted of 2-amino 2methyl 1-propanol-HCl buffer $(200 \mathrm{mM}, \mathrm{pH}$ 9.9) containing malate dehydrogenase ( 35 $\mathrm{U} / \mathrm{ml}$ ), glutamate $(50 \mathrm{mM})$, glutamic oxaloacetic transaminase $(5 \mathrm{U} / \mathrm{ml})$, and catalase $(2000 \mathrm{U} / \mathrm{ml})$. To permit the amplification of the NADH formed by enzymatic cycling, the excess $\mathrm{NAD}^{+}$was destroyed by adding $5 \mu \mathrm{l}$ of $\mathrm{NaOH}(0.35 \mathrm{~N})$ and heating for $20 \mathrm{~min}$ at $75^{\circ} \mathrm{C}$.

Step 7: Amplification. The cycling of NADH was performed with the method of Kato et al. (10). The enzyme concentrations were adjusted to cycle 1000 times. Cycling was performed on $5 \mu \mathrm{l}$ of the $27.5-\mu 1$ incuba- 


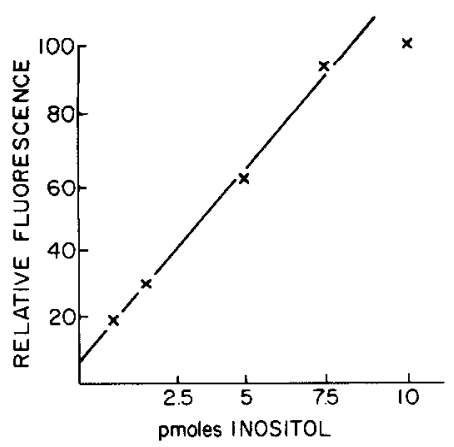

FIG. 1. Standard curve for myo-inositol determination. The points represent the means of triplicate samples.

tion mixture. Samples were cycled in 10 $\times 75-\mathrm{mm}$ borosilicate tubes with $100 \mu \mathrm{l}$ of cycling reagent. This reagent was added to samples while on ice and within a 5-min time span. The rack of samples was then incubated for $1 \mathrm{~h}$ in a $25^{\circ} \mathrm{C}$ water bath, and cycling was terminated by heating for $3 \mathrm{~min}$ in a boiling water bath.

The assay was completed by measuring the malate formed during cycling with a reagent consisting of 2-amino 2-methyl 1-propanol buffer ( $\mathrm{pH} 9.9,50 \mathrm{mM}$ ), malate dehydrogenase $(5 \mathrm{U} / \mathrm{ml})$, glutamate $(10 \mathrm{mM})$, glutamic oxaloacetic transaminase $(2 \mathrm{U} / \mathrm{ml})$, and NAD $(200 \mu \mathrm{M})$. One milliliter of this reagent was added to the cycled samples. Fluorescence was determined in a Farrand filter fluorometer following a 20 -min incubation at $25^{\circ} \mathrm{C}$.

Calculations were based on a standard curve for myo-inositol (1-10 pmol) introduced at step 5. This is depicted in Fig. 1. Recoveries of $\mathrm{IP}_{3}$ were assessed either by parallel determinations of known quantities of authentic $\mathrm{JP}_{3}$, assayed following exposure to trichloroacetic acid, or by spiking samples with $\left[{ }^{3} \mathrm{H}\right] \mathrm{IP}_{3}$ at step 1 . The observed recoveries for the overall determination of $\mathrm{IP}_{3}$ and for the individual steps are discussed below.

Materials. Biochemicals, including enzymes, were purchased from Sigma Chemical Co. (St. Louis, MO) with the following exceptions. Inositol 1,4-bisphosphate was the generous gift of Dr. William Sherman (Washington University Medical School, St. Louis, MO). Malate dehydrogenase and catalase were obtained from Boehringer-Mannheim (Indianapolis, IN). myo-[2- $\left.{ }^{3} \mathrm{H}\right]$ Inositol 1,4,5-trisphosphate was purchased from Amersham (Niles, IL). Inositol 1,2-cyclic monophosphate was synthesized by the method of Pfizer and Ballou (16) as previously described (17).

\section{RESULTS AND DISCUSSION}

Recovery. The separation of $\mathrm{IP}_{1}, \mathrm{IP}_{2}$, and $\mathrm{IP}_{3}$ by anion-exchange chromatography was confirmed by the addition of authentic inositol phosphate standards to columns containing Dowex formate resin and by the determination of myo-inositol mass following desalting and dephosphorylation. myo-Inositol could be detected only in fractions eluting with $0.2 \mathrm{M}$ ammonium formate, $0.1 \mathrm{M}$ formic acid for $\mathrm{IP}_{1} ; 0.4 \mathrm{M}$ ammonium formate, $0.1 \mathrm{M}$ formic acid for $\mathrm{IP}_{2}$; and $0.75 \mathrm{M}$ ammonium formate, $0.1 \mathrm{M}$ formic acid for $\mathrm{IP}_{3}$. The recovery of authentic $\mathrm{IP}_{3}$ added to $1 \mathrm{M}$ trichloroacetic acid and chemically measured by the eight-step assay varied between 75 and 95\%. These measurements were performed on either $100 \mathrm{pmol}$ or $1 \mathrm{nmol}$ of $\mathrm{IP}_{3}$ in duplicate during three separate determinations.

When the recovery of authentic standard was assessed at each step, it was determined that the greatest loss occurred during the removal of the $\mathrm{LiCl}$ (step 3). Whereas greater than $95 \%$ of $\left[{ }^{3} \mathrm{H}\right] \mathrm{IP}_{3}$ added to the Dowex chloride column at step 2 could be recovered by $\mathrm{LiCl}$ elution, only 70 to $95 \%$ of the labeled standard remained in the pellet following ethanol extraction. Losses at this step were even more substantial if care was not taken to remove trapped water prior to $\mathrm{LiCl}$ removal. This problem could possibly be lessened by eluting $\mathrm{IP}_{3}$ with $\mathrm{LiCl}$ at a lower concentration. However, the recovery of $\left[{ }^{3} \mathrm{H}\right] \mathrm{IP}_{3}$ from the Dowex chloride column was sub- 
stantially lower when $1.0 \mathrm{M} \mathrm{LiCl}$ or less was used. The recovery of $100 \mathrm{pmol}$ of $\mathrm{IP}_{3}$ was the smallest amount assessed. For assay of smaller amounts of $\mathrm{IP}_{3}$, recovery would need to be determined.

The recovery of $\left[{ }^{3} \mathrm{H}\right] \mathrm{IP}_{3}$ from the Dowex formate column (step 2) and following dephosphorylation (step 4) was greater than $98 \%$. The recovery of authentic unlabeled inositol as determined by the enzymatic fluorometric assay (steps 5 through 8) was greater than $95 \%$ and was determined with samples as small as 1 pmol.

Dephosphorylation. The concentration dependence of dephosphorylation with alkaline phosphatase is shown in Fig. 2. Here, $\left[{ }^{3} \mathrm{H}\right] \mathrm{IP}_{3}$ was subjected to alkaline phosphatase hydrolysis over a wide range of enzyme concentrations. Following a $2-h$ incubation, samples were separated by anion-exchange chromatography. The formation of $\mathrm{IP}_{1}, \mathrm{IP}_{2}$, and $\mathrm{IP}_{3}$ was assessed by counting the samples eluting with each buffer. The results indicate that the rates of hydrolysis are very different for the successive compounds. The curves are consistent with removal of the first phosphate at a (first-order) rate of $50 \%$ per hour with about $0.5 \mathrm{U} / \mathrm{ml}$ of enzyme, removal of the second phosphate at a tenth this rate ( $50 \%$ per hour with about $5 \mathrm{U} / \mathrm{ml}$ ), and removal of the last phosphate at a rate intermediate between the two. These data are probably indicative of the inefficiency of hydrolysis of vicinal phosphates by alkaline phosphatase. Similar observations have been reported previously for glycerophosphatidylinositides (15).

myo-Inositol determination. The fluorometric measurement of myo-inositol follows the protocol of MacGregor and Matschinsky (9) with some modifications. First, the initial oxidation of malate (step 6) is performed without the addition of $\mathrm{NAD}^{+}$. Under the conditions employed for oxaloacetate destruction, sufficient $\mathrm{NAD}^{+}$remains from the inositol oxidation step (step 5) to allow for the complete oxidation of malate.

A second change included the use of a lower concentration of oxaloacetate during the myo-inositol oxidation step.

It was observed that if myo-inositol dehydrogenase was dissolved in Tris buffer $(\mathrm{pH}$ 8.1 or 9.0 ) or in 2-amino 2-methyl 1-propanol ( $\mathrm{pH} \mathrm{9.9),} \mathrm{the} \mathrm{oxidative} \mathrm{activity} \mathrm{was}$ lost. If instead the enzyme was reconstituted

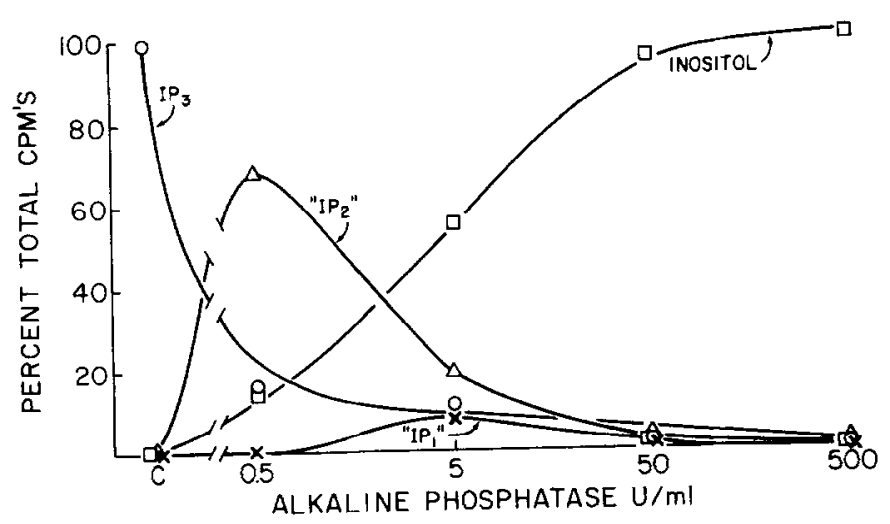

FIG. 2. The dephosphorylation of $\left[{ }^{3} \mathrm{H}\right] \mathrm{IP}_{3}$ as a function of bovine intestinal alkaline phosphatase concentration. $\left[{ }^{3} \mathrm{H}\right] \mathrm{IP}_{3}(5 \mu \mathrm{Ci})$ was subjected to alkaline phosphatase digestion as described in the text. Samples were then separated by anion-exchange chromatography. The data are expressed as the percentage of total ions. Quotation marks denote the fact that the precise structures of these compounds are unknown. Each point represents the mean of three experiments. 
TABLE 1

OXIDATION OF INOSITOL PHOSPHATES BY myo-INOSITOL DEHYDROGENASE

Inositol 100

Inositol 1,2-cyclic phosphate

Inositol 2-monophosphate

Inositol 1,4-bisphosphate

Inositol 1,4,5-trisphosphate

Note. Data are expressed as the percentage of expected malate production from the oxidation of inositol and inositol phosphates by myo-inositol dehydrogenase.

in $0.02 \mathrm{M}$ potassium phosphate buffer $(\mathrm{pH}$ 7.0 ), then oxidative activity was preserved.

Previous reports have detailed the specificity of $m y o$-inositol dehydrogenase for other sugars and sugar alcohols (9). Of the sugars tested, only glucose demonstrated significant reactivity. This is not problematic in the presently detailed method since glucose elutes with free myo-inositol in the chromatographic system employed. myo-Inositol dehydrogenase appears to be completely inactive toward the inositol phosphates (Table 1). The small amount of reactivity with $\mathrm{IP}_{1}$ probably reflects contamination with myoinositol.

Inositol trisphosphate measurements in renal cells. Preliminary determinations of $\mathrm{IP}_{3}$ mass were made in a biological system where radiolabeled $\mathrm{IP}_{3}$ has been demonstrated to increase in response to a polypeptide hormone. Specifically, when exposed to bradykinin, rabbit renal papillary-collecting tubule cells exhibit increased radiolabeling of $\mathrm{IP}_{3}$ with parallel changes in intracellular calcium mobilization and prostaglandin $\mathrm{E}_{2}$ formation $(11,18)$.

Cells were incubated with or without bradykinin $\left(10^{-7} \mathrm{M}\right)$ for $10 \mathrm{~s}$. Duplicate samples were measured in four separate experiments. Tissue blanks omitting myo-inositol dehydrogenase were 20 to $30 \%$ of the total observed fluorescence. Under these conditions, $\mathrm{IP}_{3}$ rose from $0.16 \pm 0.05$ to $0.34 \pm 0.08$ $\mathrm{pmol} / \mu \mathrm{g}$ protein ( $p<0.05$ by paired $t$ analy- sis). When intracellular volume was measured from the distribution of ${ }^{3} \mathrm{H}_{2} \mathrm{O}$ and $\left[{ }^{14} \mathrm{C}\right]$ inulin, intracellular $\mathrm{IP}_{3}$ was found to rise from $7.5 \mu \mathrm{M}$ under basal conditions to 16 $\mu \mathrm{M}$ following bradykinin stimulation.

$\mathrm{IP}_{3}$, a product of the phosphodiesteratic cleavage of phosphatidylinositol 4,5-bisphosphate, is now regarded as a potentially important second messenger in the mobilization of intracellular calcium. However, few data presently exist to confirm whether endogenous levels of $\mathrm{IP}_{3}$ are of sufficient magnitude to account for the calcium release observed with the addition of exogenous $\mathrm{IP}_{3}$ either to permeabilized cells or to intact cells via micropipets. The data detailed above are of comparable magnitude to similar observations made in thrombin-stimulated platelets (19). Moreover, the observed concentration of $\mathrm{IP}_{3}$ under kinin-stimulated conditions is close to the reported $K_{m}$ for the 5-phosphatase which degrades $\mathrm{IP}_{3}$ to $\mathrm{IP}_{2}$ $(20,21)$. However, both the basal and stimulated values of $\mathrm{IP}_{3}$ in renal cells are in excess of those concentrations demonstrated as necessary for the mobilization of intracellular calcium in permeabilized cells (4). On the one hand, this difference in concentration may reflect the failure to resolve myo-inositol 1,4,5-trisphosphate from the other inositol trisphosphate isomers under the separation conditions employed in the present study. On the other hand, $\mathrm{IP}_{3}$ concentrations may be regulated in intact cells (e.g., by compartmentalization) in ways not apparent in permeabilized cells.

In summary, a sensitive enzymatic fluorometric assay for the determination of inositol trisphosphate mass has been described. The application of this method should permit the chemical determination of myo-inositol trisphosphate levels in freshly isolated samples, tissues not amenable to radiolabeling, and small samples. Moreover, by simultaneously measuring radiolabeling and mass, it should be possible to determine the true specific activity of radiolabeled inositol phosphates. In 
this manner, a more precise determination of the kinetics of inositol phosphate formation and degradation will be possible.

\section{REFERENCES}

1. Michell, R. H. (1975) Biochim. Biophys. Acta 415, 81-147.

2. Berridge, M. J. (1984) Biochem. J. 220, 345-360.

3. Williamson, J. R., Cooper, R. H., Joseph, S. K., and Thomas, A. P. (1985) Amer. J. Physiol. 248, C203-C206.

4. Streb, H., Irvine, R. F., Berridge, M. J., and Schulz, I. (1983) Nature (London) 306, 62-69.

5. Joseph, S. K., Thomas, A. P., Williams, R. J., Irvine, R. F., and Williamson, J. R. (1984) J. Biol. Chem. 259, 3077-3081.

6. Perentki, M., Biden, T. J., Janjic, D., Irvine, R. F., Berridge, M. J., and Wolheim, C. B. (1984) $\mathrm{Na}$ ture (London) 309, 562-564.

7. Wilson, D. B., Neufeld, E. J., and Majerus, P. W. (1985) J. Biol. Chem. 260, 1046-1051.

8. Dangelmaier, C. A., Daniel, J. L., and Smith, J. B. (1986) Anal. Biochem. 154, 414-419.

9. MacGregor, L. G., and Matschinsky, F. M. (1984) Anal. Biochem. 141, 382-389.
10. Kato, T., Berger, S. J., Carter, J. A., and Lowry, O. H. (1973) Anal. Biochem. 53, 86-97.

11. Shayman, J. A., and Morrison, A. R. (1985) J. Clin. Invest. 76, 978-984.

12. Udenfriend, S., Stein, S., Bohlen, P., Dairman, W., Leimgruber, W., and Weigele, M. (1972) Science 178, 871-872.

13. Berridge, M. J. (1983) Biochem. J. 212, 849-858.

14. Batty, I. R., Nahorski, S. R., and Irvine, R. F. (1985) Biochem. J. 232, 211-215.

15. Hawkins, P. T., Michell, R. H., and Kirk, C. J. (1984) Biochem. J. 218, 785-793.

16. Pizer, F. L., and Ballou, C. E. (1959) J. Amer. Chem. Soc. 81, 915-921.

17. Shayman, J. A., Auchus, R. A., and Morrison, A. R. (1986) Biochim. Biophys. Acta 888, 171-175.

18. Shayman, J. A., Hruska, K. A., and Morrison, A. R. (1986) Bioch. Biophys. Res. Commun. 134, 299-304.

19. Rittenhouse, S., and Sasson, J. P. (1985) J. Biol. Chem. 260, 8657-8660.

20. Connolly, T. M., Bross, T. E., and Majerus, P. W. (1985) J. Biol. Chem. 260, 7868-7874.

21. Rana, R. S., Sekar, M. C., Hokin, L. E., and MacDonald, M. J. (1986) J. Biol. Chem. 261, 5237-5240. 